\title{
Cord blood levels of IL-6, IL-8 and IL-10 may be early predictors of bronchopulmonary dysplasia in preterm newborns small for gestational age
}

\author{
Gustavo Rocha $^{\mathrm{a}, *}$, Elisa Proença ${ }^{\mathrm{b}}$, Ana Guedes $^{\mathrm{b}}$, Carmen Carvalho $^{\mathrm{b}}$, Augusta Areias ${ }^{\mathrm{b}}$, \\ João Pedro Ramos ${ }^{\mathrm{c}}$, Teresa Rodrigues ${ }^{\mathrm{d}}$ and Hercília Guimarães ${ }^{\mathrm{a}, \mathrm{e}}$ \\ ${ }^{a}$ Division of Neonatology, Hospital de São João, Porto, Portugal \\ ${ }^{\mathrm{b}}$ Division of Neonatology, Centro Hospitalar do Porto, Porto, Portugal \\ ${ }^{\mathrm{c}}$ Division of Immunology, Hospital de São João, Porto, Portugal \\ ${ }^{\mathrm{d}}$ Department of Hygiene and Epidemiology, Faculty of Medicine of Porto University, Porto, Portugal \\ e Division of Neonatology, Hospital de São João, and Faculty of Medicine of Porto University, Porto, Portugal
}

\begin{abstract}
Introduction: Various cytokines have been associated to the occurrence of bronchopulmonary dysplasia (BPD) in preterm neonates.

AIM: To establish an association between cord blood cytokines and BPD, so that they could be used, in clinical practice, as early markers of BPD.

Material and methods: Preterms less than 30 weeks gestational age, were analysed by ELISA microassay for venous cord blood IL-1 $\beta$, IL-6, IL-8, TNF- $\alpha$ and IL-10, and compared between the BPD and non-BPD groups.

Results: One hundred and fifty neonates completed the study; 31 (21\%) small for gestational age (SGA); 16 were deceased before 28 days of life; 36 developed mild BPD and 20 developed moderate/severe BPD. Elevated cord blood IL- 8 was associated with death or moderate/severe BPD. SGA patients with moderate/severe BPD presented higher cord blood values of IL-8, lower IL-6 and IL-10 when compared with SGA without moderate/severe BPD; and higher IL-8 levels when compared with patients without moderate/severe BPD.

Conclusion: These results support an association between cord blood IL-8 and moderate/severe BPD, independently of the intra-uterine growth; and the association of cord blood IL-6 and IL-10 and moderate/severe BPD in SGA preterm newborns.
\end{abstract}

Keywords: Bronchopulmonary dysplasia, cytokines, inflammation, small for gestational age, preterm newborn

\section{Introduction}

Several lines of evidence suggest that intrauterine inflammation is associated both with preterm delivery and the development of chronic lung disease, often referred to as bronchopulmonary dysplasia (BPD) [9$11,19,24]$.

\footnotetext{
*Corresponding author: Gustavo Rocha, Serviço de Neonatologia/Departamento de Pediatria, Hospital de São João, Piso 2, Alameda Prof. Hernâni Monteiro, 4202-451 Porto, Portugal. Tel.: +351 225512100 extension 1949; Fax: +351 225512273; E-mail: gusrocha@oninet.pt.
}

The fetal inflammatory response syndrome (FIRS) is a condition characterized by systemic activation of the fetal innate immune system and is associated to multiorgan involvement and higher morbidity [24].

Watterberg et al. studied the association between lung inflammation and chorioamnionitis in very low birth weight preterm infants and reported a lower prevalence of respiratory distress syndrome (RDS) than in controls and a higher likelihood to develop BPD [4,40].

Antenatal exposure to pro-inflammatory cytokines such as IL- $1 \beta$, IL- 6 , IL- 8 and TNF- $\alpha$ and the occurrence of BPD have been documented in some studies [9, 
$10,23]$. IL-10 is an anti-inflammatory cytokine that promotes humoral immunity for protection against extracellular pathogens [24]. The anti-inflammatory cytokine IL-10 was less prominent in the placenta of patients with BPD compared with those without BPD. IL10 expression in the villous trophoblast layer was associated with a reduced odds ratio of developing BPD [9]. These results suggest that a placental balance between inflammatory and anti-inflammatory cytokines is crucial to normal lung organogenesis. Importantly, IL10 seems to be protective against the development of BPD [21].

Previous studies on association between inflammatory cytokines and lung lesion of the preterm newborn have been performed using amniotic fluid and tracheal aspirates, but not cord blood.

The aims of our study were to analyse the venous cord blood values of IL-1 $\beta$, IL-6, IL-8, IL-10 and TNF$\alpha$ in a cohort of preterm neonates in order to: (1) assess the association between cytokine venous cord blood levels and RDS; (2) to establish an association between cord blood cytokines levels and BPD, so that they could be used as early markers of BPD soon after birth.

\section{Material and methods}

Preterm neonates less than 30 weeks gestational age (29 weeks and 6 days, inclusive), born between January 2007 and December 2010 in two tertiary neonatal intensive care units (NICU), were selected for study. Preterm neonates affected by a TORCH infection, a chromosomal or a major congenital anomaly, twin-twin transfusion syndrome, asphyxia, any inborn error of metabolism detected during the neonatal period were excluded. Preterm neonates whose parents did not consent, were also not included.

Clinical features, including gender, gestational age, birth weight, antenatal steroid pulses, histological chorioamnionitis, intra-uterine growth restriction, neonatal morbidity, use of exogenous surfactant, oxygen therapy, mechanical ventilation and duration of NICU stay were collected. A venous cord blood sample of 4-5 $\mathrm{ml}$ was collected, immediately after birth, from the placental portion of the umbilical cord. Blood was then centrifugated and freezed between -20 and -30 degrees Celcius. Cytokines - IL-1 $\beta$, IL-6, IL-8, IL-10 and TNF- $\alpha$ - were analysed by ELISA microassay in plasma serum from the cord blood samples.

The study was approved by the institutional research ethics board of the both centres involved in the study.
The diagnosis of BPD was made according to de NIH (National Institute of Health) Consensus Definition of Bronchopulmonary Dysplasia [3]. In this study we analysed the association between BPD and cytokines for those requiring oxygen at 28 days of life (mild BPD) at 36 weeks post-menstrual age (moderate/severe BPD) and for the combined outcome death or moderate/severe BPD. Oxygen, in both centers, is used to maintain saturations given by pulse oxymetry in the range of $88 \%-94 \%$ for RDS and $90 \%-95 \%$ for BPD.

The diagnosis of acute RDS was made on a combination of clinical and radiographic features according to the criteria of the Vermont Oxford Network (VON), once our unit is a collaborative member. The VON criteria for RDS are: (1) $\mathrm{PaO}_{2}<50 \mathrm{mmHg}$ in room air, central cyanosis in room air, a requirement for supplemental oxygen to maintain $\mathrm{PaO}_{2}>50 \mathrm{mmHg}$, or a requirement for supplemental oxygen to maintain a pulse oximeter saturation over $85 \%$ within the first 24 hours of life and; (2) a chest radiograph consistent with RDS (reticulogranular appearance to lung fields with or without low lung volumes and air bronchograms) within the first 24 hours of life.

Histological chorioamnionitis was classified according to the method proposed by Blanc WA [62]: stage I - intervilositis; stage II - chorionitis; stage III - chorioamnionitis; funisitis - polymorphonuclear leukocytes in the Wharton's jelly or umbilical vessel walls; vasculitis - polymorphonuclear leukocytes in chorionic or umbilical blood vessel walls.

Chi-squared test was used to compare categorical variables and the Mann-Whitney test was used to compare two independent samples.

\section{Results}

One hundred and fifty preterm neonates were included in the study. Demographics, perinatal data, neonatal clinical data, histological chorioamnionitis and venous cord blood cytokines levels of the 150 included patients are reported in Table 1. The rate of small for gestational age (birthweight centile $<10$ of Fenton's growth charts) was $21 \%(n=31)$. Sixteen patients $(10.6 \%)$ were deceased before 28 days of life [causes of death on clinical and autopsy grounds: intraventricular haemorrhage grade IV $=5(31.3 \%)$; sepsis + pneumonia + pulmonary haemorrhage $=9(56.3 \%)$; severe respiratory distress syndrome $=1(6.2 \%)$; extreme immaturity $=1(6.2 \%)]$. One hundred and thirty four neonates were alive at 28 days of life and 36 weeks 
Table 1

Demographics, perinatal data, neonatal clinical data, histological chorioamnionitis cytokines levels of the 150 patients included in the stur

\begin{tabular}{|c|c|}
\hline Gestational age (weeks), median (min-max) & $28(24-29)$ \\
\hline Birth weight (g), median (min-max) & $1030(410-1935)$ \\
\hline Small for gestational age, $\mathrm{n}(\%)$ & $31(21)$ \\
\hline \multicolumn{2}{|l|}{ Gender, n (\%) } \\
\hline Male & $72(48)$ \\
\hline Female & $78(52)$ \\
\hline Antenatal steroids, n (\%) & $147(98)$ \\
\hline Full cycle & $102(68)$ \\
\hline C-section, n (\%) & $104(69)$ \\
\hline Respiratory distress syndrome, $\mathrm{n}(\%)$ & $124(83)$ \\
\hline Surfactant, n (\%) & $111(74)$ \\
\hline Invasive mechanical ventilation, $\mathrm{n}(\%)$ & $104(69)$ \\
\hline \multicolumn{2}{|l|}{ Bronchopulmonary dysplasia* } \\
\hline Mild, n (\%) & $36(27)$ \\
\hline Moderate/severe, n (\%) & $20(15)$ \\
\hline Patent ductus arteriosus, $\mathrm{n}(\%)$ & $35(23)$ \\
\hline Necrotizing enterocolitis $(\geqslant 2 \mathrm{~A}), \mathrm{n}(\%)$ & $9(6)$ \\
\hline Sepsis, $\mathrm{n}(\%)$ & $87(58)$ \\
\hline Intraventricular haemorrhage-grades III + IV, n (\%) & $14(9)$ \\
\hline Periventricular leukomalacia, $\mathrm{n}(\%)$ & $6(4)$ \\
\hline Retinopathy of prematurity grade $\geqslant \mathbf{2}, \mathrm{n}(\%)^{*}$ & $7(5)$ \\
\hline Deceased before 28 days of life, n (\%) & $16(11)$ \\
\hline Deceased after 36 weeks, n (\%) & $3(2)$ \\
\hline Length of stay (days), median $(\min -\max )^{*}$ & $69(43-124)$ \\
\hline Histological chorioamnionitis, $\mathrm{n}(\%)$ & $64(43)$ \\
\hline Grade I, n $(\%)$ & $35(23)$ \\
\hline Grade II, n (\%) & $15(10)$ \\
\hline Grade III, n (\%) & $14(9)$ \\
\hline Funisitis, n (\%) & $13(9)$ \\
\hline Chorionic vasculitis, $\mathrm{n}(\%)$ & $13(9)$ \\
\hline \multicolumn{2}{|l|}{ Cord blood cytokine levels, pg/ml, median (min-max) } \\
\hline Interleukin-1 $\beta$ (IL-1 $\beta$ ) & $3.8(0.1-230.2)$ \\
\hline Interleukin-6 (IL-6) & $7.7(0-430)$ \\
\hline Interleukin-8 (IL-8) & $105.7(0-970.5)$ \\
\hline Interleukin-10 (IL-10) & $8.8(0-119)$ \\
\hline Tumor necrosis factor alpha (TNF- $\alpha)$ & $15.0(0-910.2)$ \\
\hline
\end{tabular}

of post-menstrual age. Three neonates $(2 \%)$ deceased after 36 weeks post-menstrual age, two deaths were sepsis related and one child with BPD died because of respiratory failure.

Comparison of venous cord blood cytokines between patients deceased before 28 days of life and patients alive at 36 weeks of post-menstrual age is reported in Table 2. Patients deceased before 28 days of life presented significant lower gestational age and birthweight. Cord blood levels of IL-8 were significantly higher in patients deceased before 28 days of life ( $p=$ $0.004)$, and this significance was present after adjustment for gestational age: odds ratio (OR) 1.004 [CI 95\%: 1.001-1.008] ( $p=0.014)$.

We did not find any significant association between the analysed venous cord blood cytokines and the occurrence of RDS.
No significant associations were found between cord blood cytokines and mild BPD (for both groups: patients alive at day 28 of life; and for the combined outcome death or dependency of oxygen on day 28 of life).

No significant associations were found between cord blood cytokines and moderate/severe BPD considering the patients alive at 36 weeks post-menstrual age. Nevertheless, IL- 8 cord blood levels were significantly higher in the group with combined outcome death or moderate/severe BPD (median 218.9 vs. 96.6 pg/ml, $p<0.001$ ), Table 3. This significance was present after adjustment for gestational age, OR 1.004 [CI 95\%: 1.001-1.006] ( $p=0.004)$.

The association between intra-uterine growth and moderate/severe BPD is reported in Tables 4 (moderate/severe BPD) and 5 (combined outcome death 
Table 2

Comparison of demographics, perinatal data and venous cord blood cytokines between the 134 neonates alive at 36 post-menstrual age (PMA) and the 16 patients deceased before 28 days of life

\begin{tabular}{|c|c|c|c|}
\hline & Alive at 36 weeks PMA $(n=134)$ & Deceased before 28 days of life $(n=16)$ & $\mathrm{p}$ \\
\hline Gestational age (weeks), median (IQ range) & $29(28-29)$ & $25(24-27)$ & $<0.001 \S$ \\
\hline Birth weight $(\mathrm{g})$, median $(\min -\max )$ & $1050(410-1935)$ & $772.5(560-1290)$ & $0.001 \S$ \\
\hline Small for gestational age, $\mathrm{n}(\%)$ & $31(23)$ & $0(0)$ & $<\mathbf{0 . 0 0 1}^{*}$ \\
\hline C-section, $\mathrm{n}(\%)$ & $97(73)$ & $7(44)$ & $0.047^{*}$ \\
\hline Antenatal steroids, n (\%) & $131(98)$ & $16(100)$ & $0.985^{*}$ \\
\hline Full cycle, n $(\%)$ & $95(71)$ & $7(44)$ & $0.001 *$ \\
\hline Histological chorioamnionitis, $\mathrm{n}(\%)$ & $58(43)$ & $6(38)$ & $0.354^{*}$ \\
\hline \multicolumn{4}{|l|}{$\begin{array}{l}\text { Cord blood cytokine levels, } \mathrm{pg} / \mathrm{ml} \\
\text { median (min-max) }\end{array}$} \\
\hline Interleukin-1 $\beta$ (IL-1 $\beta$ ) & $3.7(0.1-48.3)$ & $13.3(0.5-230)$ & $0.338 \S$ \\
\hline Interleukin-6 (IL-6) & $7.9(0-430)$ & $6.6(1.2-429.8)$ & $0.493 \S$ \\
\hline Interleukin-8 (IL-8) & $100.5(0-970.5)$ & $223.8(71.4-605.8)$ & $0.004 \S$ \\
\hline Interleukin-10 (IL-10) & $8.5(0-119)$ & $22.3(0-115.5)$ & $0.069 \S$ \\
\hline Tumor necrosis factor alpha (TNF- $\alpha$ ) & $14.9(0-910.2)$ & $21.4(6.8-186.1)$ & $0.308 \S$ \\
\hline
\end{tabular}

§Mann-Whitney test; *Chi-squared test; IQ - interquartil.

Table 3

Comparison of demographics, histological chorioamnionitis, sepsis and cord blood cytokines levels between the combined outcome death or moderate/severe BPD (oxygen requirement at 36 weeks) and no-BPD groups. [Note: patients deceased before day 28 of life $(n=16)$ included]

\begin{tabular}{|c|c|c|c|}
\hline & $\begin{array}{l}\text { Death or moderate/severe BPD present } \\
\qquad(n=36)\end{array}$ & $\begin{array}{l}\text { Death or moderate/severe BPD absent } \\
\qquad(n=114)\end{array}$ & $\mathrm{p}$ \\
\hline Gestational age, weeks, median (IQ range) & $28(25-29)$ & $28(28-29)$ & $0.040 \S$ \\
\hline Birthweight, grams, median (min-max) & $807(410-1290)$ & $1135(410-1935)$ & $0.091 \S$ \\
\hline Gender, male $\mathrm{n}(\%) /$ female, $\mathrm{n}(\%)$ & $19(53) / 17(47)$ & $53(46) / 61(54)$ & $0.767^{*}$ \\
\hline Small for gestational age, $\mathrm{n}(\%)$ & $20(56)$ & $11(10)$ & $0.410^{*}$ \\
\hline C-section, n (\%) & $24(67)$ & $80(70)$ & $0.986^{*}$ \\
\hline Deceased, $\mathrm{n}(\%)$ & $16(44)$ & $0(0)$ & $<0.001^{*}$ \\
\hline Histological chorioamnionitis (all grades), $\mathrm{n}(\%)$ & $14(39)$ & $50(44)$ & $0.432^{*}$ \\
\hline IL-1 $\beta, \mathrm{pg} / \mathrm{ml}$, median (min-max) & $7.8(0.2-230)$ & $3.7(0.1-48.3)$ & $0.800 \S$ \\
\hline IL-6, pg/ml, median (min-max) & $6.2(0.2-429.8)$ & $8.5(0-430)$ & $0.082 \S$ \\
\hline IL-8, pg/ml, median (min-max) & $218.9(11-605.8)$ & $96.6(0-970.5)$ & $<\mathbf{0 . 0 0 1 \S}$ \\
\hline IL-10, pg/ml, median (min-max) & $4.7(0-115.5)$ & $9.2(0-119)$ & $0.725 \S$ \\
\hline TNF- $\alpha, p g / m l$, median (min-max) & $14.9(3.9-186.1)$ & $15.1(0-910.2)$ & $0.857 \S$ \\
\hline
\end{tabular}

§Mann-Whitney test; *Chi-Squared test; IQ - interquartil.

or moderate/severe BPD). Small for gestational age preterm neonates with moderate/severe BPD presented significantly higher levels of cord blood IL-8 and lower levels of IL-6 and IL-10 when compared to SGA without moderate/severe BPD. IL-8 was also significantly elevated in the appropriate for gestational age group with combined outcome death or moderate/severe BPD $(p=0.003)$. Small for gestational age preterm neonates with moderate/severe BPD presented significantly higher levels of cord blood IL-8 without moderate/severe BPD, Table 6.

Small for gestational age patients were more likely born by $\mathrm{C}$-section than the appropriate for gestational age group, although the prevalence of chorioamnionitis was not significantly different in both groups, Table 7 . The association between histological chorioamnionitis (all grades) and delivery mode was not significant (41\% of chorio in C-section group vs $46 \%$ of chorio in vaginal delivery, $p=0.382$ ). No significant associations were found between the analysed cord blood cytokines and the mode of delivery (C-section vs vaginal delivery).

No significant associations were found between the analysed cord blood cytokines and histological choriamnionitis (all grades of chorioamnionitis, and the most severe histological patterns with funisitis and/or chorionic vasculitis).

\section{Discussion}

Exposure to intra-amniotic inflammation induces fetal lung maturity, which favours survival in the context of preterm delivery. However, chronic exposure to microbial products and inflammatory mediators induce 
Table 4

Cord blood cytokines levels for moderate/severe BPD (oxygen requirement at 36 weeks) according to intra-uterine growth. (Note: patients deceased before day 28 of life not included)

\begin{tabular}{|c|c|c|c|c|}
\hline & Cord blood cytokine levels & Moderate/severe BPD present & Moderate/severe BPD absent & $\mathrm{p}$ \\
\hline \multirow[t]{5}{*}{ SGA $n=\mathbf{3 1}$} & IL-1 $\beta, \mathrm{pg} / \mathrm{ml}$, median (min-max) & $8.8(0.7-22.0)$ & $3.7(0.2-45.0)$ & $0.721 \S$ \\
\hline & IL-6, pg/ml, median (min-max) & $2.1(0.2-280.5)$ & $8.2(2.4-279)$ & $0.021 \S$ \\
\hline & IL-8, pg/ml, median (min-max) & $150.1(61.1-392.5)$ & $73.5(0-520)$ & $\mathbf{0 . 0 3 7} \S$ \\
\hline & IL-10, pg/ml, median (min-max) & $3.1(0-27.6)$ & $11.3(0-82.0)$ & $0.045 \S$ \\
\hline & TNF $-\alpha, \mathrm{pg} / \mathrm{ml}$, median $(\min -\max )$ & $13.8(6.9-96.1)$ & $18(3.9-910.2)$ & $0.345 \S$ \\
\hline \multirow[t]{5}{*}{ AGA $n=103$} & IL-1 $\beta, \mathrm{pg} / \mathrm{ml}$, median (min-max) & $7.1(0.2-48.3)$ & $3.7(0.1-48.0)$ & $0.872 \S$ \\
\hline & IL-6, pg/ml, median (min-max) & $9.35(0-183)$ & $8.6(0.2-430.0)$ & $0.914 \S$ \\
\hline & IL-8, pg/ml, median (min-max) & $96.7(16.1-864.5)$ & $110.6(0-970.5)$ & $0.646 \S$ \\
\hline & IL-10, pg/ml, median (min-max) & $6.8(0-36.3)$ & $12.3(0-119)$ & $0.091 \S$ \\
\hline & TNF- $\alpha, \mathrm{pg} / \mathrm{ml}$, median (min-max) & $14.2(0-414.7)$ & $15(3.2-147.9)$ & $0.649 \S$ \\
\hline
\end{tabular}

AGA - appropriate for gestational age; SGA - small for gestational age; $\S$ - Mann-Whitney test.

Table 5

Cord blood cytokines levels for combined outcome death or moderate/severe BPD (oxygen requirement at 36 weeks) according to intra-uterine growth. [Patients deceased before 28 days of life $(n=16)$ included]

\begin{tabular}{|c|c|c|c|c|}
\hline & Cord blood cytokine levels & $\begin{array}{c}\text { Death or moderate/severe } \\
\text { BPD present }\end{array}$ & $\begin{array}{c}\text { Death or moderate/severe } \\
\text { BPD absent }\end{array}$ & $\mathrm{p}$ \\
\hline \multirow[t]{5}{*}{ SGA $n=31$} & $\mathrm{IL}-1 \beta, \mathrm{pg} / \mathrm{ml}$, median (min-max) & $4.7(0.2-24.1)$ & $3.7(0.2-45.0)$ & $0.853 \S$ \\
\hline & IL-6, pg/ml, median (min-max) & $4.3(0.2-280.5)$ & $7.7(2.4-279.0)$ & $0.470 \S$ \\
\hline & IL-8, pg/ml, median (min-max) & $161.8(11.0-520)$ & $33.6(0-102.6)$ & $<0.001 \S$ \\
\hline & IL-10, pg/ml, median (min-max) & $3.2(0-29.4)$ & $12.5(0-82.0)$ & $\mathbf{0 . 0 3 9} \S$ \\
\hline & TNF- $\alpha, \mathrm{pg} / \mathrm{ml}$, median $(\min -\max )$ & $13.3(3.9-112.4)$ & $23.6(4.3-910.2)$ & $0.083 \S$ \\
\hline \multirow[t]{5}{*}{ AGA $n=119$} & IL-1 $\beta, \mathrm{pg} / \mathrm{ml}$, median (min-max) & $13.3(0.5-230.2)$ & $3.7(0.1-48.3)$ & $0.391 \S$ \\
\hline & IL-6, pg/ml, median (min-max) & $6.6(1.2-429.8)$ & $8.6(0-430.0)$ & $0.321 \S$ \\
\hline & IL-8, pg/ml, median (min-max) & $223.8(71.4-605.8)$ & $100.5(0-970.5)$ & $0.003 \S$ \\
\hline & IL-10, pg/ml, median (min-max) & $22.3(0-115.5)$ & $8.5(0-119.0)$ & $0.084 \S$ \\
\hline & TNF- $\alpha, \mathrm{pg} / \mathrm{ml}$, median (min-max) & $21.4(6.8-186.1)$ & $14.8(0-414.7)$ & $0.218 \S$ \\
\hline
\end{tabular}

AGA - appropriate for gestational age; SGA - small for gestational age; $\S$ - Mann-Whitney test.

Table 6

Comparison of cytokines levels between SGA with moderate/severe bronchopulmonary dysplasia (BPD) and no-BPD patients. (Note: patients deceased before day 28 of life not included)

\begin{tabular}{lcrc}
\hline Cord blood cytokine levels & $\begin{array}{c}\text { SGA with moderate/severe BPD present } \\
(n=20)\end{array}$ & $\begin{array}{c}\text { Moderate/severe BPD absent } \\
(n=114)\end{array}$ & $\mathrm{p}$ \\
\hline IL-1 $\beta, \mathrm{pg} / \mathrm{ml}$, median (min-max) & $8.8(0.7-22.0)$ & $3.7(0.1-48.3)$ & $0.713 \S$ \\
IL-6, pg/ml, median (min-max) & $2.1(0.2-280.5)$ & $8.2(0-430.0)$ & $0.103 \S$ \\
IL-8, pg/ml, median (min-max) & $150.1(61.1-392.5)$ & $100.5(0-970.5)$ & $\mathbf{0 . 0 0 5} \S$ \\
IL-10, pg/ml, median (min-max) & $3.1(0-27.6)$ & $8.8(0-119.0)$ & $0.052 \S$ \\
TNF- $\alpha$, pg/ml, median (min-max) & $13.8(6.9-96.1)$ & $14.9(0-910.2)$ & $0.538 \S$ \\
\hline
\end{tabular}

AGA - appropriate for gestational age; SGA - small for gestational age; $\S$ - Mann-Whitney test.

profound changes in the developmental program of the lung (alveoli and vasculature). Therefore, the short term gain in lung maturity can extract a price, which is the predisposition to the development of chronic lung disease. Clearly, the pathogenesis of BPD results from a combination of immaturity, oxygen toxicity, and mechanical damage during the course of ventilation, and also antenatal inflammation [24].

Cytokines are small soluble peptides or glycoproteins, whose primary function is intercellular communication. They are produced and act on leukocytes, endothelium, and other cells. They play a major role in the control of the inflammatory response through the regulation of: (1) the innate immune response; (2) the adaptive immune response; and (3) the growth and differentiation of hematopoietic cells [24].

IL- $1 \beta$ is a pro-inflammatory cytokine considered to be a central mediator of septic shock and is associated to many of the clinical manifestations of sepsis, such as fever, hypotension, leukocytosis [24]. IL-1 $\beta$ has been shown to be increased in bronchoalveolar lavage fluid [6,56] and in blood plasma [49] of preterm infants that developed BPD. KE Willet et al. reported that the intra-amniotic injection of IL- $1 \beta$ induces in- 
Table 7

Association between delivery mode (C-section) and chorioamnionitis with intra-uterine growth

\begin{tabular}{lccc}
\hline & SGA $(n=31)$ & AGA $(n=119)$ & p \\
\hline C-section, n (\%) & $28(90)$ & $76(64)$ & $\mathbf{0 . 0 0 1}$ \\
Chorioamnionitis (all grades), $\mathrm{n}(\%)$ & $14(45)$ & $50(42)$ & $0.762^{*}$ \\
\hline AGA - appropriate for gestational age; SGA - small for gestational age; ${ }^{*}$ Chi-squared test.
\end{tabular}

flammation and maturation in fetal sheep lung [41]. A link between inflammation and disturbed retinoic acid pathway was demonstrated for the first time by K Bry and U Lappalainen [3]. K. Bry et al. also demonstrated in bitransgenic mice that IL- $1 \beta$ disrupted alveolar septation [33].

IL-6 measurement in amniotic fluid is a sensitive test for the prospective diagnosis of acute histologic chorioamnionitis and the identification of neonates at risk for significant morbidity (including BPD) and mortality $[9,11]$. Increased activity of IL-6 has also been demonstrated in consecutive lung lavage samples of premature infants that developed BPD $[1,13,39,50,56$, $60]$. Recently, the role of FIRS has been emerged as a possible mechanism of serious neonatal morbidity [26, 52].

Amniotic fluid IL-8 concentrations have been shown to be elevated in neonates that subsequently develop BPD [23]. IL-8 is a potent neutrophil chemoattractant and has been reported to be increased in bronchoalveolar lavage fluid of premature infants at risk of chronic lung disease $[9,20,64]$.

IL-10 is an anti-inflammatory cytokine that may have a protective role in acute lung injury. IL-10 is a potent inhibitor of lipopolysaccharide-stimulated release of IL- 8 and MIP (macrophage inflammatory protein -1 alpha) from neutrophils of the newborn via a mechanism not involving nuclear factor-kappa B activity [31]. Low IL-10 production has been linked to the development of BPD $[2,21,42,54]$ suggesting that IL-10 is protective against the development of BPD.

TNF- $\alpha$, as IL- $1 \beta$, is a pro-inflammatory cytokine considered to be a central mediator of septic shock, and there is also evidence supporting the role of TNF- $\alpha$ in the mechanisms of preterm parturition [19]. Significant elevations of TNF- $\alpha$ in tracheal aspirate fluids of BPD patients have been demonstrated in animal and human studies [5,30].

In this study, IL-8 venous cord blood values were significantly elevated in patients that developed moderate/severe BPD when the outcome death or moderate/severe BPD was considered. IL-8 was associated to a lower gestational age as it was shown to be significantly increased in the most premature neonates that were deceased in the first days or weeks of life. IL-8 was also elevated in small for gestational age preterm newborns with moderate/severe BPD when compared to small for gestational age neonates without BPD, and when compared with the overall patients that did not develop BPD.

In this studt, cord blood IL-1beta, IL-6 and TNF- $\alpha$ were not associated to BPD.

A relevant finding in this study was the cord levels of IL-6, IL-8 and IL-10, that were significantly associated to the requirement of oxygen at 36 weeks of post-menstrual age in small for gestational age preterm newborns.

Small for gestational age and intra-uterine growth restriction are fetal conditions that increase the risk of BPD and prolong the duration of mechanical ventilation in preterm infants younger than 32 weeks of gestation $[28,32,43]$. The main mechanisms to explain how intra-uterine growth restriction modulates the risk of a BPD have been described in animals. In experimentally growth restricted preterm lambs, impaired growth of terminal airways, gas exchange units and blood vessels have been shown [44,51]. Furthermore, growth restriction leads to reduced expression of surfactant protein mRNA and could induce increase inflammatory activation [44].

While elevated levels of pro-inflammatory cytokines are clearly associated with preterm birth, the relation between cytokines and fetal growth is not so clear. Some studies have addressed this issue. GI Neta et al. observed that levels of interferon gamma (IFN-gamma) in cord blood may be related to fetal growth restriction [27]. G Amarilio et al. observed significant elevations of IL-6, TNF- $\alpha, \mathrm{C}$ reactive protein and thrombopoietin in cord blood of small for gestational age term and near term newborns compared with the appropriate for gestational age controls, suggesting that the pathological picture of chronic fetal hypoxia observed in intrauterine growth restriction shares features with the inflammatory response [25]. Elevation of maternal and umbilical serum levels of IL- 8 and TNF- $\alpha$ have been observed in patients with preeclampsia with intrauterine growth restriction and these levels were significantly higher than in patients with preeclampsia with normal fetal growth $[29,45,48,55]$. KD Heyborn and coworkers, to further define the role of abnormal 
immune activation and suppression in mediating impaired fetal growth, measured levels of IL-10 in amniotic fluid samples and observed that IL-10 levels in small for gestational age samples were elevated compared to controls, supporting the role of an abnormal immune activation, as opposed to inadequate immune suppression, in mediating impaired fetal growth [38]. AG Rijhsinghani et al. demonstrated that the administration of anti IL-10 monoclonal antibodies to pregnant mice did not alter the duration of gestation, however, it appeared to be associated with transient neonatal growth deficiency [7].

Preeclampsia has been shown to be associated with reduction of some cytokines within the amniotic fluid compartment and concomitant reactive augmentation of other cytokines within the maternal and fetal organism [58]. Intra-uterine growth retardation has been shown to be associated with increased levels of TNF$\alpha$ in the amniotic fluid, whereas the cytokines G-CSF, GM-CSF, and IL-1 were reduced [59]. Not only inflammatory disease but also intra-uterine growth retardation is characterized by a changing cytokine pattern.

RA Odergard et al. demonstrated that in severe preeclampsia, cord plasma IL-6 concentration was lower than among controls. The strong association between low IL-6 levels and low birth weight ratio appeared to be present mainly in early-onset disease versus late onset disease [53]. T Hata et al. investigated the participation of cytokines in fetal distress and observed that fetal distress causes an elevation of immune factors such as IL-6, IL-8 and granulocyte elastase (GEL) [57]. ME Street et al. observed higher levels of IL-6 in placenta lysates of growth restricted newborns than in appropriate for gestational age. IL-6 in lysates was negatively correlated with birth length, weight and head circumference [46]. BK Rinehart et al. observed increased expression of IL-1beta, IL-10 and TNF- $\alpha$ in placentas of preeclampsia patients and suggest that this may be in association with placental hypoxia and may contribute to the global endothelial dysfunction observed in preeclampsia [8].

The insulin growth factor system is central to fetal growth. ME Street et al. demonstrated that the placenta of fetal growth restricted neonates presented higher IGF-II, IGFBP-1, IGFBP-2, and IL-6 contents compared with controls [47]. Another study confirmed a close relationship among IGF-II, IL-6 and fetal growth [22].

Cytokines have also been implicated in normal and hypoplastic lung development. Many cytokines are produced by different lung cells at various stages of fetal development. Cytokines present in amniotic fluid or in the blood stream may reach the fetal lungs. Some cytokines, including epidermal growth factor, transforming growth factor-alpha, and interferon-gamma have been shown to stimulate the production of surfactant components [35]. IL-1 in amniotic fluid has been shown to promote lung maturation in preterm newborns [36]. IL-1 has also been associated to the degree of maturity of surfactant proteins and the direction of its effect seems to change significantly along the fetal period [61]. C Nogueira-Silva et al. studied the role of IL-6 on fetal lung growth and observed that there is a physiological role for this cytokine on pulmonary branching mechanisms, most likely involving p38-MAPK intracellular signalling pathway [15]. Also, blocking IL-6 activity significantly diminished the intrinsic capacity of hypoplastic fetal lungs to recover from hypoplasia and attenuated their daily branching rates [58]. There is some evidence that IL-4 decreases human airway smooth muscle cell proliferation [37]. Inflammatory mediators regulate the insulin-like growth factors (IGF) system, a key modulator of lung fibroblast proliferation. The activity of IGFs is regulated by IGF-binding proteins (IGFBPs) secreted by lung cells. WA Price et al. demonstrated that various cytokines regulate IGFBP production and clearance by fetal lung cells suggesting a mechanism by which cytokines regulate cell proliferation following lung injury [63].

\section{Conclusion}

The results of this study support the idea that not only inflammatory disease but also intra-uterine growth retardation is characterized by a changing cytokine pattern. Our results highlight the existence of an association between elevated venous cord blood IL- 8 and moderate/severe BPD, independently of the intra-uterine growth; and the association of low levels of venous cord blood IL-6 and IL-10 and moderate/severe BPD in small for gestational age preterm newborns.

\section{Acknowledgements}

The authors would like to thank Luísa Almeida, Gabriela Figueiredo and Conceição Gonçalves for the collaboration given in the laboratory processing of the blood samples; and to the Delivery Room staff and Services of Obstetrics from Hospital de São João and 
Maternidade Júlio Dinis for the collaboration given in blood samples collection.

This study was supported by the Scholarship for Investigation 2005 of the Portuguese Society of Neonatology, granted by Abbott Laboratories.

\section{References}

[1] A Bagchi, RM Viscardi, V Taciak, JE Ensor, KA McCrea, JD Hasday. Increased activity of interleukin- 6 but not tumor necrosis factor-alpha in lung lavage of premature infants is associated with the development of bronchopulmonary dysplasia. Pediatr Res 1994; 36: 244-52.

[2] A Garingo, L Tesoriero, R Cayabyab, M Durand, M Blahnik, S Sardesai, R Ramanathan, C Jones, K Kwong, C Li, P Minoo. Constitutive IL-10 expression by lung inflammatory cells and risk for bronchopulmonary dysplasia. Pediatr Res 2007; 61: 197-202.

[3] A Jobe, E Bancalari. NICHD/NHLBI/ORD Workshop Summary - Bronchopulmonary Dysplasia. Am J Respir Crit Care Med 2001; 163: 1723-9.

[4] AH Jobe. Antenatal associations with lung maturation and infection. J Perinatol 2005; 25 (suppl 2): S31-S35.

[5] A Lyon. Chronic lung disease of prematurity. The role of intrauterine infection. Eur J Pediatr 2000; 159: 798-802

[6] AM Patterson, V Taciak, J Lovchic, RE Fox, AB Campbel, RM Viscardi. Ureaplasm urealyticum respiratory tract colonization is associated with an increase in IL 1-beta and tumor necrosis factor alpha relative to interleukin 6 in tracheal aspirates of preterm infants. Pediatr Infect Dis 1998; 17: 321-8.

[7] AG Rijhsinghani, K Thompson, L Tygrette, SK Bathia. Inhibition of interleukin-10 during pregnancy results in neonatal growth retardation. Am J Reprod Immunol 1997; 37: 323-5.

[8] BK Rinehart, DA Terrone, S Lagoo-Deenadayalan, WH Barber, EA Hale, JN Jr Martin, WA Bennett. Expression of the placental cytokines tumor necrosis factor alpha, interleukin 1beta, and interleukin 10 is increased in preeclampsia. Am J Obstet Gynecol 1999; 181: 915-20.

[9] BH Su, HY Chiu, TW Lin, HC Lin. Interleukin-8 in bronchoalveolar lavage fluid of premature infants at risk of chronic lung disease. J Formos Med Assoc 2005; 104: 244-8.

[10] BH Yoon, R Romero, JK Jun, KH Park, JD Park, F Ghezzi, BI Kim. Amniotic fluid cytokines (interleukin-6, tumor necrosis factor-alpha, interleukin-1 beta, and interleukin-8) and the risk for the development of bronchopulmonary dysplasia. Am J Obstet Gynecol 1997; 177: 825-30.

[11] BH Yoon, R Romero, KS Kim, JS Park, SH Ki, BI Kim, JK Jun. A systemic fetal inflammatory response and the development of bronchopulmonary dysplasia. Am J Obstet Gynecol 1999; 181: 773-9.

[12] BH Yoon, R Romero, CJ Kim, JK Jun, R Gomez, JH Choi, HC Syn. Amniotic fluid interleukin-6: a sensitive test for antenatal diagnosis of acute inflammatory lesions or preterm placenta and prediction of perinatal morbidity. Am J Obstet Gynecol 1995; 172: 960-70.

[13] CW Choi, BI Kim, HS Kim, JD Park, JH Choi, DW Son. Increase in interleukin- 6 in tracheal aspirate at birth: a predictior of subsequent bronchopulmonary dysplasia in preterm infants. Acta Paediatr 2006; 95: 38-43.

[14] C Nogueira-Silva, M Santos, MJ Baptista, RS Moura, J Correia-Pinto. IL-6 is constitutively expressed during lung morphogenesis and enhances fetal lung explant branching. Pediatr Res 2006; 60: 530-6.

[15] C Nogueira-Silva, RS Moura, N Esteves, S Gonzaga, J Correia-Pinto. Intrinsic catch-growth of hypoplastic fetal lungs is mediated by interleukin-6. Pediatr Pulmonol 2008; 43: 680-9.

[16] CP Speer. Inflammatory mechanisms in neonatal chronic lung disease. Eur J Pediatr 1999; 158 (suppl 1): S18-S22.

[17] CP Speer. New insights into the pathogenesis of pulmonary inflammation in preterm infants. Biol Neonate 2001; 79: 2059.

[18] CP Speer. Inflammation and bronchopulmonary dysplasia. Semin Neonatol 2003; 8: 29-38.

[19] CP Speer. Pulmonary inflammation and bronchopulmonary dysplasia. J Perinatol 2006; 26 (suppl 1): S57-S62.

[20] DY Li, J Wu, XY Zhang, ZC Fen. Expression of IL-8, SP-A and TGF-beta1 in bronchoalveolar lavage fluid of neonates with bronchopulmonary dysplasia. Zhongguo Dang Dai Er Ke Za Zhi 2010; 12: 444-6.

[21] EC McGowan, S Kostadinov, K McLean, F Gotsch, D Venturini, R Romero, AR Laptook, S Sharma. Placental IL-10 dysregulation and association with bronchopulmonary dysplasia risk. Pediatr Res 2009; 66: 455-60.

[22] F Foltran, P Berchialla, S Bernasconi, E Grossi, D Gregori, ME Street. A systems biology approach: new insights into fetal growth restriction using Bayesian Networks. J Biol Regul Homeost Agents 2011; 25: 269-77.

[23] F Ghezzi, R Gomez, R Romero, BH Yoon, SS Edwin, C David, J Janisse, M Mazor. Elevated interleukin- 8 concentrations in amniotic fluid of mothers whose neonates subsequently develop bronchopulmonary dysplasia. Eur J Obstet Gynecol Reprod Biol 1998; 78: 5-10.

[24] F Gotsch, R Romero, JP Kusanovic, S Mazaki-Tovi, BL Pineles, O Erez, J Espinoza, SS Hassan. The fetal inflammatory response syndrome. Clin Obstet Gynecol 2007; 50: 652-83.

[25] G Amarilyo, A Oren, FB Mimouni, Y Ochsorn, V Deutsch, D Mandel. Increased cord serum inflammatory markers in smallfor-gestational-age neonates. J Perinatol 2011; 31: 30-2

[26] G Erdei, P Tóth, B Vásárhelyi. New clinical entity in perinatology: fetal inflammatory response syndrome. Orv Hetil. 2003; 144: 1515-9.

[27] GI Neta, OS von Ehrenstein, LR Goldman, K Lum, R Sundaram, W Andrews, J Zhang. Umbilical cord serum cytokine levels and risks of small-for-gestational-age and preterm birth. Am J Epidemiol 2010; 171: 859-67.

[28] G Kewitz, S Wudel, H Hopp, W Hopfenmuller, M Vogel, I Roots. Below median birth weight in appropriate-forgestational-age preterm infants as a risk factor for bronchopulmonary dysplasia. J Perinat Med 2008; 36: 359-64.

[29] JL Bartha, R Romero-Carmona, R Comino-Delgado. Inflammatory cytokines in intrauterine growth retardation. Acta $\mathrm{Ob}$ stet Gynecol Scand 2003; 82: 1099-102.

[30] JJ Coalson, VT Winter, T Siler-Khodr, BA Yoder. Neonatal chronic lung disease in extremely immature baboons. Am J Respir Crit Care Med 1999; 160: 1333-46.

[31] J Tryzmel, V Miskolci, S Castro-Alcaraz, I Vancurova, D Davidson. Interleukin-10 inhibits proinflammatory chemokine release by neutrophils of the newborn without suppression of nuclear factor kappa B. Pediatr Res 2003; 54: 382-6.

[32] J Zeitlin, M El Ayoubi, PH Jarreau, ES Draper, B Blondel, W Kunzel, M Cuttini, M Kaminski, L Gortner, P Van Reempts, E Kollée, MOSAIC Research Group. J Pediatr 2010; 157: 733-9. 
[33] K Bry, JA Whitsett, U Lappalainen. IL-1beta disrupts postnatal lung morphogenesis in the mouse. Am J Respir Cell Mol Biol 2007; 36: 32-42.

[34] K Bry, U Lappalainen. Pathogenesis of bronchopulmonary dysplasia: the role of interleukin 1 beta in the regulation of inflammation-mediated pulmonary retinoic acid pathways in transgenic mice. Semin Perinatol 2006; 30: 121-8.

[35] K Bry, U Lappalainen, M Hallman. Cytokines and production of surfactant components. Semin Perinatol 1996, Jun; 20: 194205.

[36] K Bry, U Lappalainen, M Hallman. Intraamniotic interleukin1 accelerates surfactant protein synthesis in fetal rabbits and improves lung stability after premature birth. J Clin Invest 1997, 99: 2992-9.

[37] KM Hawker, PR Johnson, JM Hughes, JL Black. Interleukin4 inhibits mitogen-induced proliferation of human airway smooth muscle cells in culture. Am J Physiol 1998; 275: L469-77.

[38] KD Heyborne, JA McGregor, G Henry, SS Witkin, JS Abrams. Interleukin-10 in amniotic fluid at midtrimester: immune activation and suppression in relation to fetal growth. Am J Obstet Gynecol 1994; 171: 55-9.

[39] K Tullus, GW Noack, LG Burman, R Nilson, B Wretlind, A Brauner. Elevated cytokine levels in tracheobronchial aspirate fluids from ventilator treated neonates with bronchopulmonary dysplasia. Eur J Pediatr 1996; 155: 112-6.

[40] KL Watterberg, LM Demers, SM Scott, S Murphy. Chorioamnionitis and early lung inflammation in infants in whom bronchopulmonary dysplasia develops. Pediatrics 1996; 97: 2105 .

[41] KE Willet, BW Kramer, SG Kallapur, M Ikegami, JP Newnham, TJ Moss, PD Sly, AH Jobe. Intra-amniotic injection of IL-1 induces inflammation and maturation in fetal sheep lung. Am J Physiol Lung Cell Mol Physiol 2002; 282: L411-20.

[42] K Yanamandra, P Boggs, J Loggins, RJ Baier. Interleukin-10 -1082 G/A polymorphism and risk of death or bronchopulmonary dysplasia in ventilated very low birth weight infants. Pediatr Pulmonol 2005; 39: 426-32.

[43] L Gortner, I Reiss, A Hilgendorff. Bronchopulmonary dysplasia and intra-uterine growth restriction. The Lancet 2006; 368: 1.

[44] L Gortner, A Hilgendorff, T Bahner, M Ebsen, I Reiss, S Rudloff. Hypoxia-induced intra-uterine growth retardation: effects on pulmonary development and surfactant protein transcription. Biol Neonate 2005; 88: 129-35.

[45] M Laskwowska, K Laskwoska, B Leszczynska-Gorzelak, J Oleszczuk. Comparative analysis of the maternal and umbilical interleukin- 8 levels in normal pregnancies and in pregnancies complicated by preeclampsia with intrauterine normal growth and intrauterine growth retardation. J Matern Fetal Neonatal Med 2007; 20: 527-32.

[46] ME Street, C Volta, MA Ziveri, I Viani, S Bernasconi. Markers of insulin sensitivity in placentas and cord serum of intrauterine growth-restricted newborns. Clin Endocrinol (Oxf) 2009; 71: 394-9.

[47] ME Street, P Seghini, S Fieni, MA Ziveri, C Volta, D Martorana, I Viani, D Gramellini, S Bernasconi. Changes in interleukin-6 and IGF system and their relationships in placenta and cord blood in newborns with fetal growth restriction compared with controls. Eur J Endocrinol 2006; 155: 567-74.

[48] M Tosun, H Celik, B Avci, E Yavuz, T Alper, E Malatyalioglu. Maternal and umbilical serum levels of interleukin-6, interleulin-8, and tumor necrosis factor-alpha in normal preg- nancies and in pregnancies complicated by preeclampsia. $\mathrm{J}$ Matern Fetal Neonatal Med 2010; 23: 880-6.

49] N Ambalavanan, WA Carlo, CT DÁngio, SA Mc Donald, A Das, D Schendel, P Thorsen, RD Higgins. Cytokines associated with bronchopulmonary dysplasia or death in extremely low birth weight infants. Pediatrics 2009; 123: 1132-41.

[50] P von Bismarck, A Claass, C Schickor, MF Krause, S RoseJohn. Altered pulmonary interleukin-6 signaling in preterm infants developing bronchopulmonary dysplasia. Exp Lung Res 2008; 34: 694-706.

[51] PJ Rozance, GJ Seedorf, A Brown, G Roe, MC O’Meara, J Gien, JR Tank, SH Abman. Intrauterine growth restriction decreases pulmonary alveolar and vessel growth and causes pulmonary artery endothelial cell dysfunction in vitro fetal sheep. Am J Physiol Lung Cell Mol Physiol 2011; 301: L86171.

52] R Mittendorf, R Covert, AG Montag, W elMasri, J Muraskas, KS Lee, PG Pryde. Special relationship between fetal inflammatory response syndrome and bronchopulmonary dysplasia in neonates. J Perinat Med 2005; 33: 428-34.

[53] RA Odegard, LJ Vatten, ST Nilsen, KA Salvesen, H Vefring, $\mathrm{R}$ Austgulen. Umbilical cord plasma interleukin-6 and fetal growth restriction in preeclampsia: a prospective study in Norway. Obstet Gynecol 2001; 98: 289-94.

[54] R Paananen, AK Husa, R Vuolteenaho, R Herva, T Kaukola, M Hallman. Blood cytokines during the perinatal period in very preterm infants: relationship of inflammatory response and bronchopulmonary dysplasia. J Pediatr 2009; 154: 39-43.

[55] R Raghupathy, M Al-Azemi, F Azizieh. Intrauterine growth restriction: cytokine profiles of trophoblast antigen-stimulated maternal lymphocytes. Clin Dev Immunol 2012; 2012: 734865.

[56] S Kotecha, L Wilson, A Wangoo, M Silverman, RJ Shaw. Increase in interleukin (IL)-1 beta and IL-6 in bronchoalveolar lavage fluid obtained from infants with chronic lung disease of prematurity. Pediatr Res 1996; 40: 250-6.

[57] T Hata, T Kawamura, K Inada, R Fujiwaki, Y Ariyuki, K Hata, M Kitao. Interleukin-6, interleukin-8, and granulocyte elastase in newborns with fetal distress. Gynecol Obstet Invest 1996; 42: 174-7.

[58] T Stallmach, G Hebisch, H Joller, P Kolditz, M Engelmann. Expression pattern of cytokines in the different compartments of the feto-maternal unit under various conditions. Reprod Fertil Dev 1995; 7: 1573-80.

[59] T Stallmach, G Hebisch, HI Joller-Jemelka, P Orban, J Schwaller, M Engelmann. Cytokine production and visualized effects in the feto-maternal unit. Quantitative and topographic data on cytokines during intrauterine disease. Lab Invest 1995; 73: 384-92.

[60] UK Munshi, JO Niu, MM Siddiq, LA Parton. Elevation of interleukin-8 and interleukin-6 preceds the influx of neutrophils in tracheal aspirates from preterm infants who develop bronchopulmonary dysplasia. Pediatr Pulmonol 1997; 24: 331-6.

[61] V Glummoff, O Vayrinen, T Kangas, M Hallman. Degree of lung maturity determines the direction of the interleukin-1induced effect on the expression of surfactant proteins. Am J Respir Cell Moll Biol, 2000; 22: 280-8.

[62] WA Blanc. Pathology of the placenta, membranes, and umbilical cord in bacterial, fungal, and viral infections in man. In: Naeye RL, Kissane JM, eds. International Academy of Pathology Monograph. Perinatal Diseases by 14 authors. Baltimore, Williams and Willkins, 1981. 
[63] WA Price, BM Moats-Saats, AD Stiles. Pro and antiinflammatory cytokines regulates insulin-like growth factor binding protein production by fetal rat lung fibroblasts. Am J Respir Cell Mol Biol 2002; 26: 283-9.
[64] Z Zentay, M Sharaf, M Qadir, D Drafta, D Davidson. Mechanism for dexamethasone inhibition of neutrophil migration upon exposure to lipopolysaccharide in vitro: role of neutrophil interleukin-8 release. Pediatr Res 1999; 46: 406-10. 


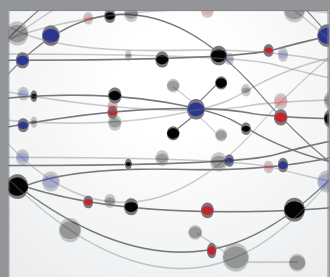

The Scientific World Journal
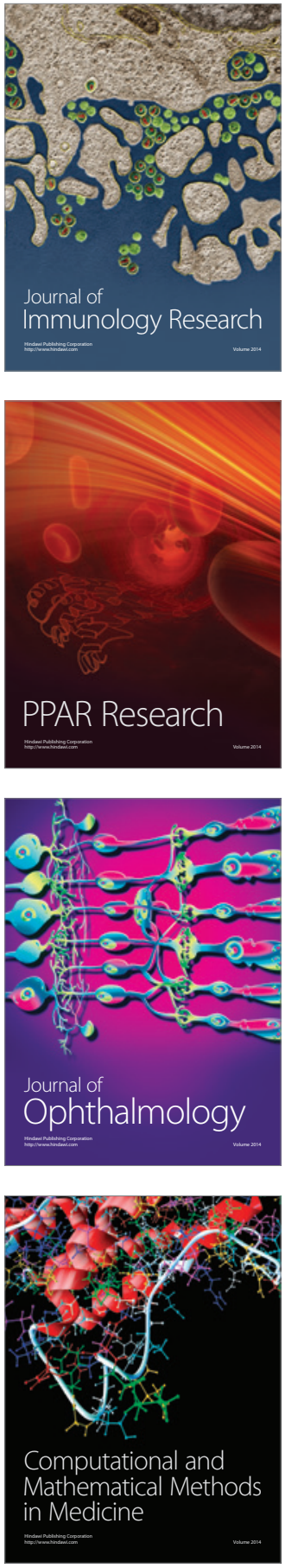

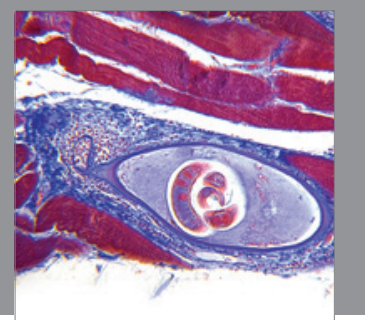

Gastroenterology

Research and Practice
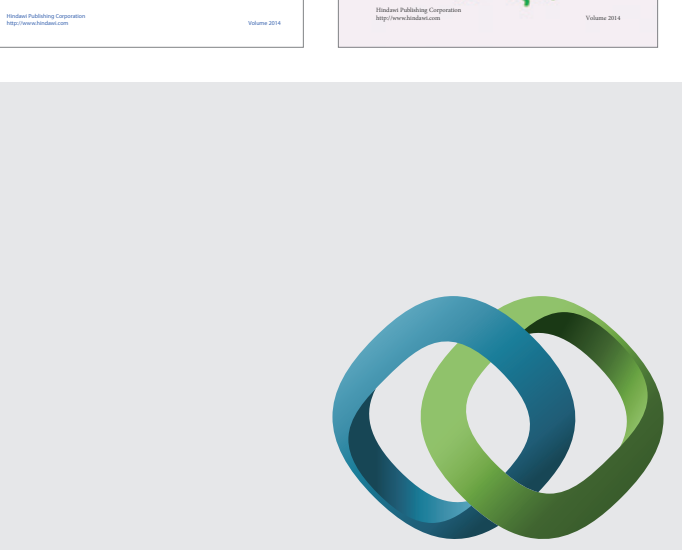

\section{Hindawi}

Submit your manuscripts at

http://www.hindawi.com
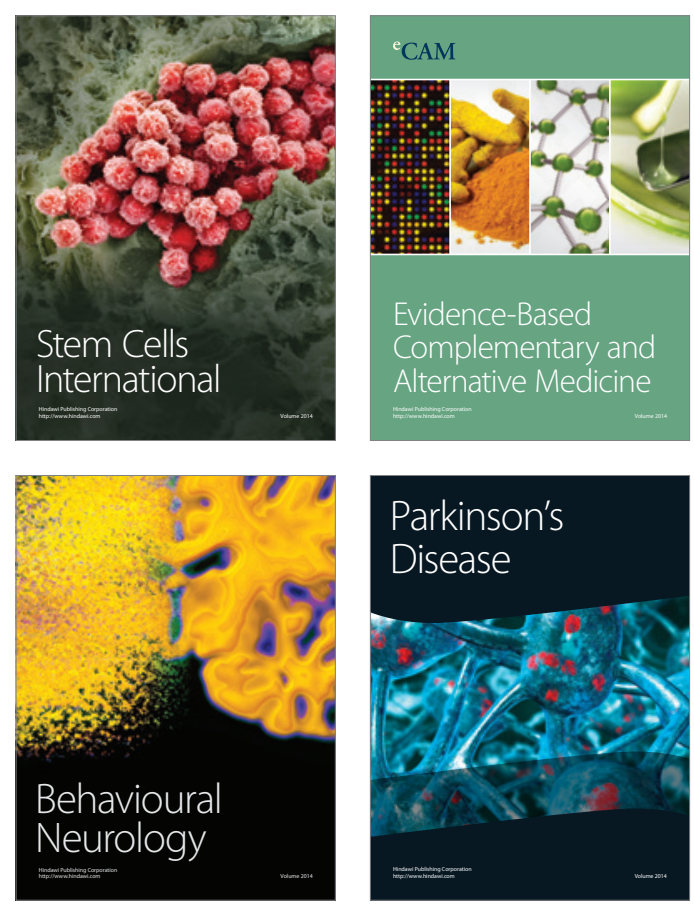

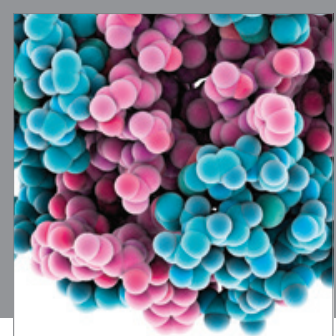

Journal of
Diabetes Research

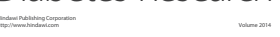

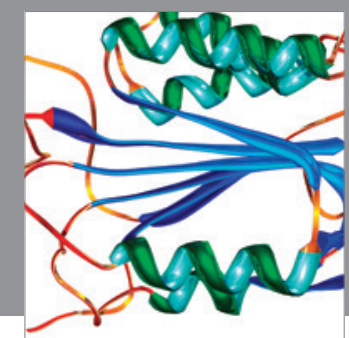

Disease Markers
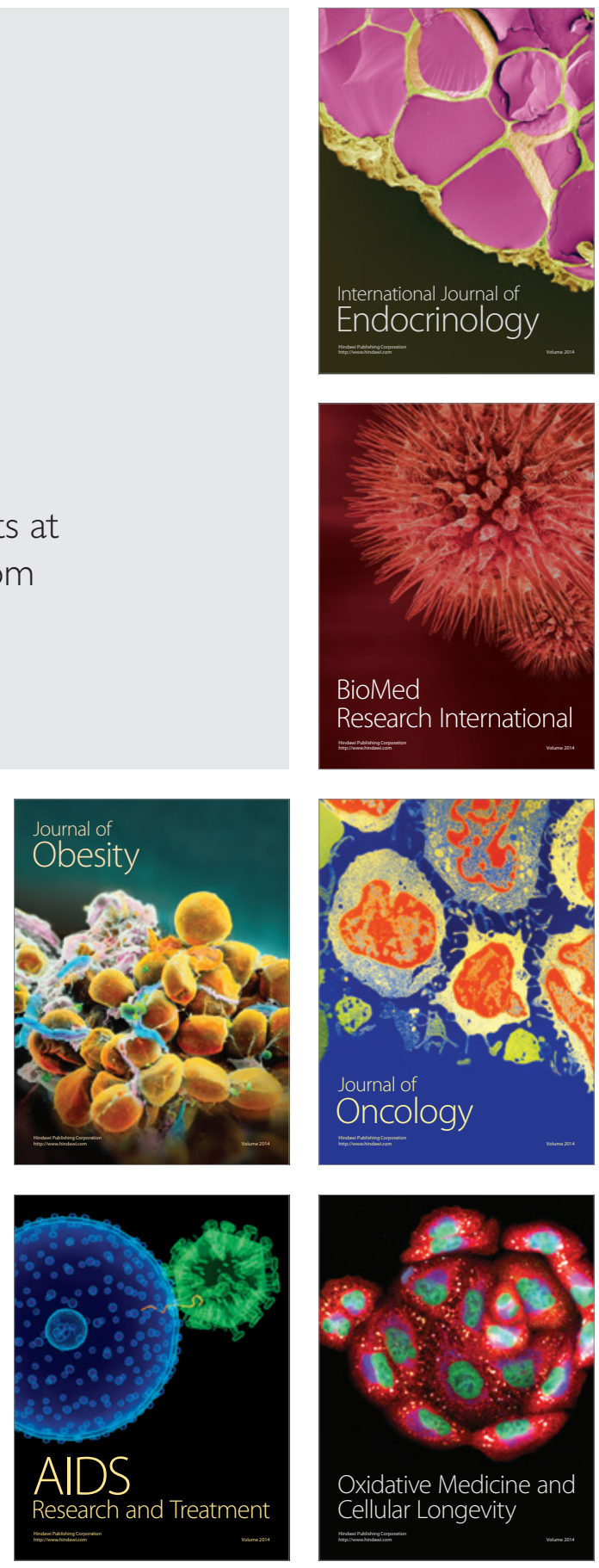